Document downloaded from:

http://hdl.handle.net/10251/48843

This paper must be cited as:

González Medina, R.; Patrao Herrero, I.; Gabriel Garcerá; Figueres Amorós, E. (2012). A low-cost photovoltaic emulator for static and dynamic evaluation of photovoltaic power converters and facilities. Progress in Photovoltaics. 1-15. doi:10.1002/pip.2243.

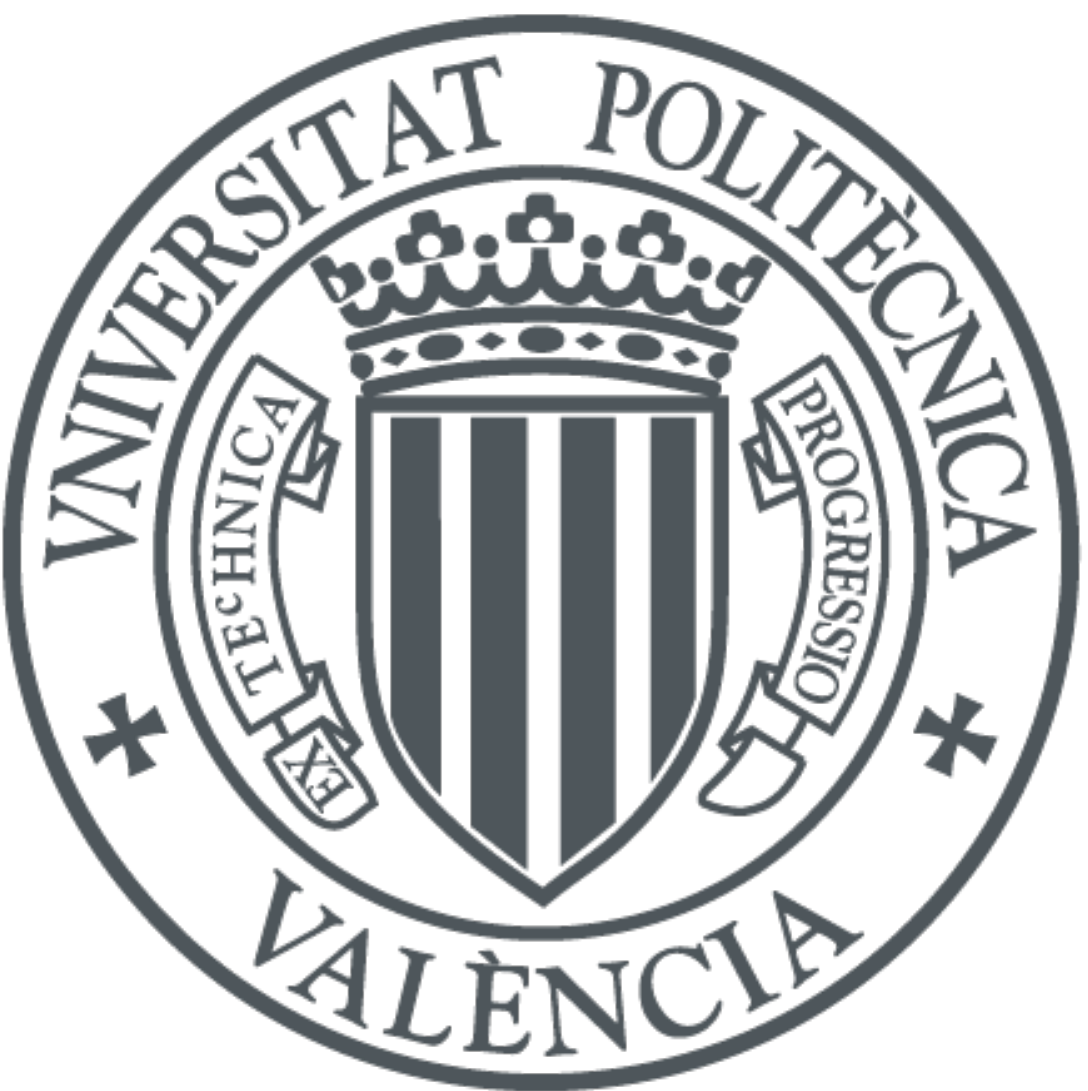

The final publication is available at

http://dx.doi.org/10.1002/pip.2243

Copyright Wiley

Additional Information 


\title{
A low-cost photovoltaic emulator for static and dynamic evaluation of PV power converters and facilities
}

\begin{abstract}
For testing maximum power point tracking (MPPT) algorithms running on electronic power converters for photovoltaic (PV) applications, it is required either a PV energy source (PV module or PV array) or a PV emulator. With a PV emulator it is possible to control the testing conditions with accuracy, so that it is the preferred option. The photovoltaic source is modeled as a current source, thus the emulator has to work as a current source dependent on its output voltage. The proposed emulator is a buck converter with an average current mode control loop, which allows testing the static and dynamic performance of PV facilities up to $3 \mathrm{~kW}$. In order to validate the concept, the emulator is used to evaluate the MPPT algorithm of a $230 \mathrm{~W}$ experimental microinverter working from a single PV module.
\end{abstract}

\section{Keywords}

Photovoltaic emulator, photovoltaic simulator, MPPT testing, photovoltaic inverter

\section{Introduction}

Every electronic power converter for photovoltaic applications must be tested under realistic operating conditions, since a PV energy source presents a particular relationship between its output voltage and current. Testing of the power converter with varying characteristics of the PV source is very important, as it is part of the validation of the final product [1]-[3].

When testing a PV power converter there are two options: to test the converter with a real PV energy source (either a PV module or an array of PV modules), or to test it with a PV emulator. When using a real PV source, it is necessary to have a wide space in the testing facility, especially at high power. Besides, it is difficult to set the testing conditions due to the weather dependency. Furthermore, it is necessary to acquire the meteorological conditions (irradiance and temperature) [4], which is expensive and difficult, whereas they can vary during the test [5], [6].

When using a PV emulator, it is easy to set the testing conditions with accuracy, whereas the testing equipment requires a smaller space and cost. Besides, it is very easy to change the test conditions (number and connection of the PV modules, irradiance, temperature, I-V characteristic curve...), regardless the weather conditions [7].

Power inverters for photovoltaic applications have been evolving to include lower power converters. A few years ago the most common converters were the central inverters [8], with a power level higher than $50 \mathrm{~kW}$. At the present time, the most 
common inverters are the string inverters [8], with a few kilowatts power (2-10 kW). Nowadays, the microinverters are an emerging technology gaining an increasing interest, due to their modularity and the possibility of single module maximum power point tracking [9]. A microinverter is a grid-connected inverter operating from a single PV module, working from a low input voltage $(<50 \mathrm{~V})$ and providing an output power up to $300 \mathrm{~W}$.

Commercial PV emulators present several drawbacks, as a high cost and the impossibility of emulating rapidly changing atmospheric conditions [6]. In this paper a low cost photovoltaic emulator based on a buck DC-DC converter [10] and a currentvoltage lookup-table is proposed. The emulator is able to simulate the current-voltage curve of a PV source of $3 \mathrm{~kW}$ maximum output power. It can be used to test the performance of inverters in photovoltaic applications.

A switched mode buck dc-dc converter is a good solution for a low cost emulator as its worst case efficiency is around 90\%, resulting in a low cost thermal design and a small volume. Linear topologies present a much lower efficiency (35\% in some cases), leading to a bulky converter and an expensive thermal design.

A prototype of the proposed emulator has been designed and tested connected to a photovoltaic microinverter in order to evaluate its performance.

\section{Photovoltaic source model}

A photovoltaic source consists of the series interconnection of several PV cells, which convert the solar radiation to electrical energy. The produced electrical energy is affected by the irradiance level and the temperature of the cell. Each cell has a nonlinear electrical characteristic I-V curve [11], and the association of cells (or modules) yields a characteristic curve strongly affected by the most shaded one [12].

It is possible to obtain an equation of the characteristic I-V curve using the mathematical model presented in [13]. However, manufacturers of photovoltaic sources, instead of the current-voltage parameters of the equation, provide experimental data of the I-V curves with irradiance and temperature as running parameters. For this reason, the PV emulator described in this paper uses a lookup table to model the PV source.

In grid-connected applications the most common PV modules provide around 220W power at their maximum power point (MPP), at an irradiance level of $1000 \mathrm{~W} / \mathrm{m} 2$ and a temperature of $25{ }^{\circ} \mathrm{C}$. The typical I-V and P-V (power-voltage) curves of one of these modules are shown in Figure 1 (a commercial SLK60P6L module by Siliken S.A.). For a given irradiance level and temperature, there is a characteristic relationship between the output voltage and the current generated. Thus, the behavior of a PV source can be emulated by means of a current source controlled by its output voltage [15]. 
In Figure 1 it can be observed the relationship between irradiance and the parameters of the curve: short-circuit current is strongly affected, the open circuit voltage is slightly affected and both the MPP voltage and power vary with the irradiance. This variation justifies the importance of the MPPT algorithm, ensuring that the inverter tracks the MPP in any climatic condition.
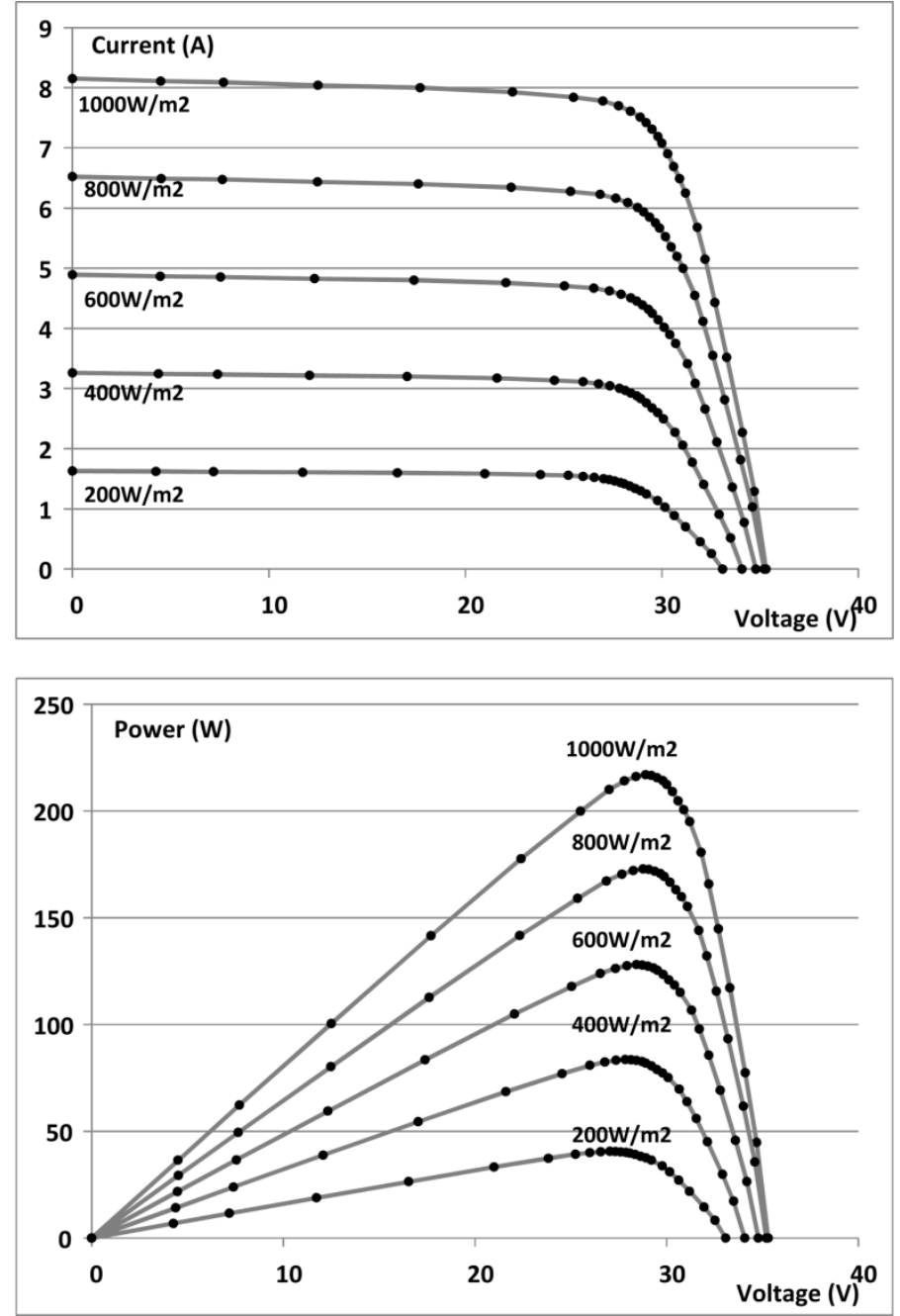

Figure 1: I-V and P-V characteristics of a commercial SLK60P6L PV module and its dependency of the irradiance. The ambient temperature is $25^{\circ} \mathrm{C}$.

In addition to the irradiance, the temperature also affects the performance of the photovoltaic source. The variation of the I-V and P-V curves with temperature for an irradiance level of $1000 \mathrm{~W} / \mathrm{m}^{2}$ is shown in Figure 2. It can be observed how a higher temperature reduces both the maximum available power and the MPP voltage. 

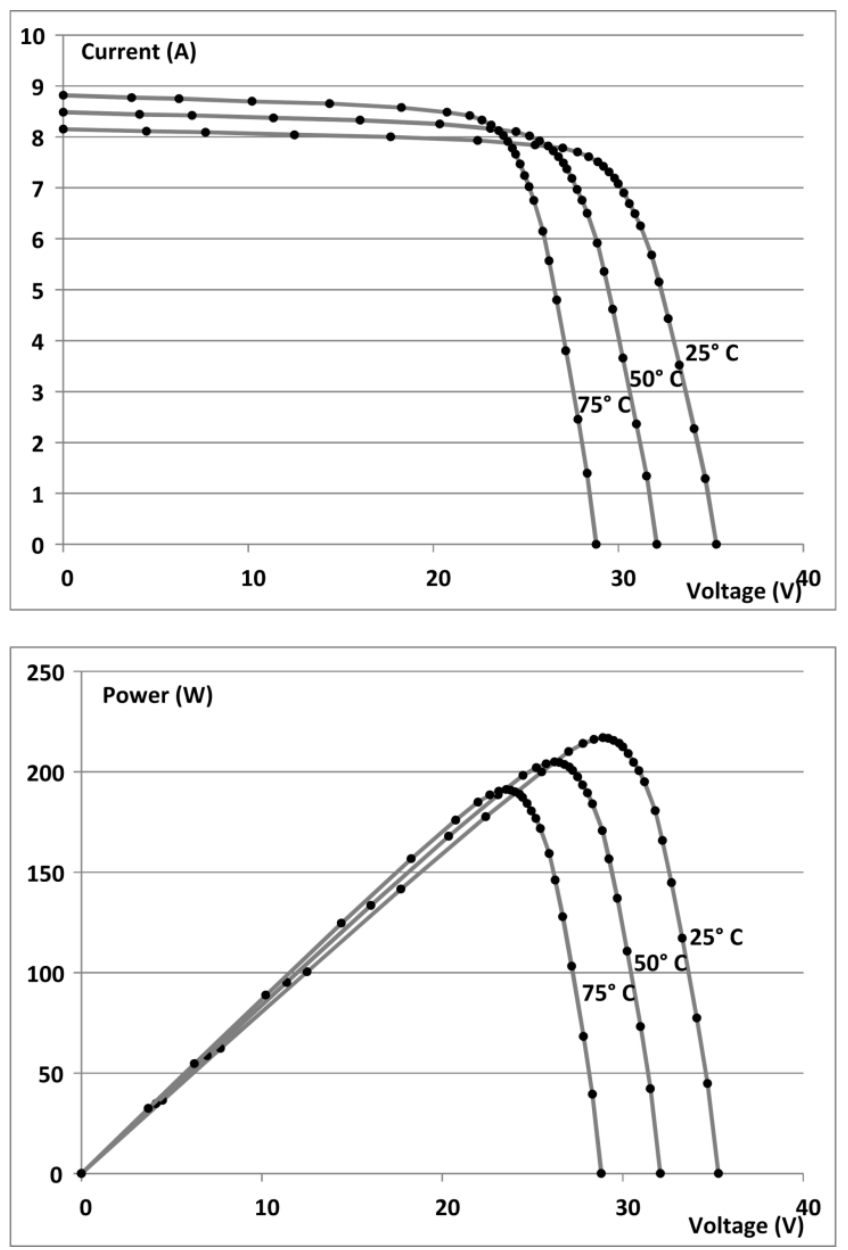

Figure 2: I-V and P-V characteristics of a commercial SLK60P6L PV module and its dependency of temperature. The irradiance level is $1000 \mathrm{~W} / \mathrm{m}^{2}$.

\section{Photovoltaic emulator}

In PV inverters it is important to obtain a high accuracy from the MPPT algorithm to reach the maximun power point (MPP) of the photovoltaic source, as it strongly affects the overall power generation of the photovoltaic installation. The MPPT algorithm is responsible for searching the MPP and keeping the inverter working at this point under all operating conditions such as different irradiance levels and temperature [16].

When researching about MPPT methods, it is mandatory to have a reliable PV emulator that assures the repeatability of the results, capable of simulating all the possible climatic conditions (variations of irradiance and temperature) [17]. However, commercial emulators have a high economic cost [7]. For instance, an Agilent solar array emulator of $60 \mathrm{~V} / 8 \mathrm{~A}(\mathrm{E} 4350 \mathrm{~B})$ has a cost about $\$ 10.000$, whereas its output range is quite limited.

Most advanced emulators incorporate a microcontroller and provide to the user the possibility of introducing the I-V curve of a photovoltaic source at several irradiance levels. It is also possible to emulate the evolution of a PV generator during a long period 
of time (1 day, for example) if the software allows to program the evolution of irradiance and temperature during this period.

The PV emulator proposed in this paper can simulate the behaviour of PV power source with an open circuit voltage of $500 \mathrm{~V}$ (maximum voltage) and a short-circuit current of 9A (maximum current), with a power limitation of 3000W. As the proposed emulator is based on a microcontroller, it can emulate the evolution of the panel I-V curve for a long period of time. An important objective of the proposal is to get a low cost emulator.

In the proposed PV emulator a 26 points lookup table is created in order to model the PV source. The lookup table is organized according to voltage values with a higher density of points around the MPP and in the open-circuit zone than in the constant current zone. This strategy provides a great resolution with a short table. The type of the interpolation implemented between adjacent points is linear, since it provides enough accuracy with a low computational cost. The points stored in the table can be observed in Figure 1and in Figure 2 (black dots).

A block diagram of the proposed emulator is shown in Figure 3. The power stage acts as a current source dependent on its output voltage, being both magnitudes related by means of the I-V curves stored as lookup tables. A lookup table stores the I-V curve to be emulated and generates the reference value of the output current. The irradiance and temperature parameters affect the generated curve. A microcontroller allows to recalculate the I-V curve "on the fly" in order to emulate the transient behaviour of a PV source. The points belonging to each new I-V curve are updated at $5 \mathrm{kHz}$. This is done by means of interpolation along the stored curves, corresponding to different irradiance and temperature levels. The current controller ensures the tracking of the reference value for this current. Since a photovoltaic source acts as a current source, it is not neccesary to implement a voltage control loop: the lookup table is enough.

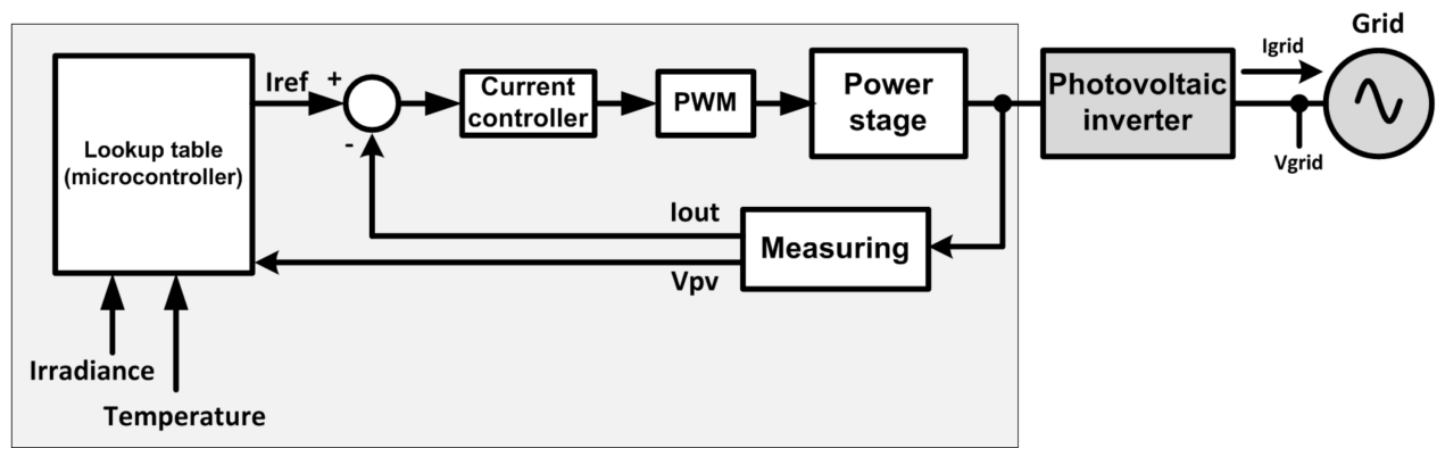

Figure 3: Block diagram of the proposed emulator feeding a grid-connected PV inverter.

The topology used for the power stage is a buck DC-DC converter [18], since it is simple and reliable. As it is a switching converter, the power losses will be low, whereas the converter will have a low size and cost . To supply the buck power stage it is necessary to use a DC power source with a voltage higher than the open-circuit voltage of the PV source being emulated. 
To achieve a crossover frequency of $10 \mathrm{kHz}$, a ten times higher $(100 \mathrm{kHz})$ switching frequency has been chosen. This is a usual criterion when implementing a linear control of buck DC-DC converters, because the linear small-signal models of switching converters are only valid up to half the switching frequency [20]. Besides, if the switching noise is pushed to $100 \mathrm{kHz}$, a loop with a $10 \mathrm{kHz}$ crossover frequency is not greatly affected by the switching noise.

Taking the switching frequency into account, the chosen power transistor for the buck converter is a MOSFET, since other transistors like IGBTs present high switching power losses above $50 \mathrm{kHz}$ and at $520 \mathrm{~V}$ input voltage. A crossover frequency of $10 \mathrm{kHz}$ ensures that the emulator is much faster than the PV inverter under test (i.e. much faster than the inverter MPPT algorithm), so that the inverter "sees" the emulator as a real PV source. The crossover frequency of the inverter voltage control loop is usually in the range $1-20 \mathrm{~Hz}$. Thus, the dynamics of the current controller of the PV source emulator does not affect the dynamics of the inverter under test.

In order to achieve a small size and a low cost of the PV emulator a buck dc-dc converter running at $100 \mathrm{kHz}$ with a single stage LC filter is proposed, with a control crossover frequency of $10 \mathrm{kHz}$. The problems of using low switching frequencies are the need of big output filters, like the double stage LC filter proposed in [15], and that the control bandwidth is limited, so that a good dynamic response is difficult to obtain. The need of big filters is not only a size problem, but also a price problem. The proposed buck dc-dc converter uses a single stage LC filter, resulting in a small size and a low cost as it will be shown later. The value of the filter capacitor is very small compared with the typical DC-link input capacitance of PV inverters connected to the emulator, so that the inverter dynamics is not affected by this small and unexpensive capacitor. This capacitor is necessary to reduce the switching ripple from the emulator output voltage in applications that do not provide an input capacitance, as the test of an emulated PV source loaded by a resistive load. The software-emulated I-V characteristic proposed in this paper provides a high flexibility to set the irradiance and temperature of the PV source being emulated.

A simplified electronic scheme of the PV emulator proposed in this paper is shown in Figure 4. In this figure the emulator is feeding a grid-connected PV inverter. A low cost microcontroller (Microchip dsPIC33FJ64GP802) senses the output voltage and searches in the chosen I-V curve the corresponding reference value of the output current, stored in a lookup table. This current reference value is provided to the PI current controller through a digital to analog converter (DAC). The analog PI controller ensures the tracking of the current reference value with a closed loop bandwidth around $10 \mathrm{kHz}$. This control scheme corresponds to average current mode control [19]. The PWM modulator adjusts the duty cycle of the buck MOSFET transistor. An isolated driver provides the isolation required between the control circuitry and the MOSFET.

To achieve a crossover frequency as high as $10 \mathrm{kHz}$, a 10 times higher sampling frequency $(100 \mathrm{kHz})$ is needed in practice. Since it is difficult to run a digital controller 
at a sampling frequency of $100 \mathrm{kHz}$ with a low cost microcontroller, the PI controller is implemented by means of operational amplifiers.

Instead of sensing the current provided to the PV converter under test, the current through the buck converter output inductor (which agrees with the shunt current) is sensed, because the latter allows the implementation of average current mode control. It is worth pointing out that the current provided to the PV converter, $\mathrm{I}_{\mathrm{PV}}$, has the same average value as the current through the buck inductor, $\mathrm{I}_{\text {out }}$, so that by controlling $\mathrm{I}_{\text {out }}$ the current $\mathrm{I}_{\mathrm{PV}}$ is indirectly controlled. The values of the components of the buck circuit are: $\mathrm{L}=1.87 \mathrm{mH}$, Cout $=16 \mu \mathrm{F}$, Cin $=8 \mu \mathrm{F}$. The emulator is capable of providing an output voltage $\mathrm{V}_{\text {out }}$ from $10 \mathrm{~V}$ to $490 \mathrm{~V}$ with a maximum output power of $3000 \mathrm{~W}$. The overall cost of the implemented prototype is about $\$ 210$, having performed the purchase of the electronic components on a small-scale basis. At an industrial manufacturing scale the production cost would be much lower. As the DC power source is not a part of the emulator, it is not included in the prototype cost.

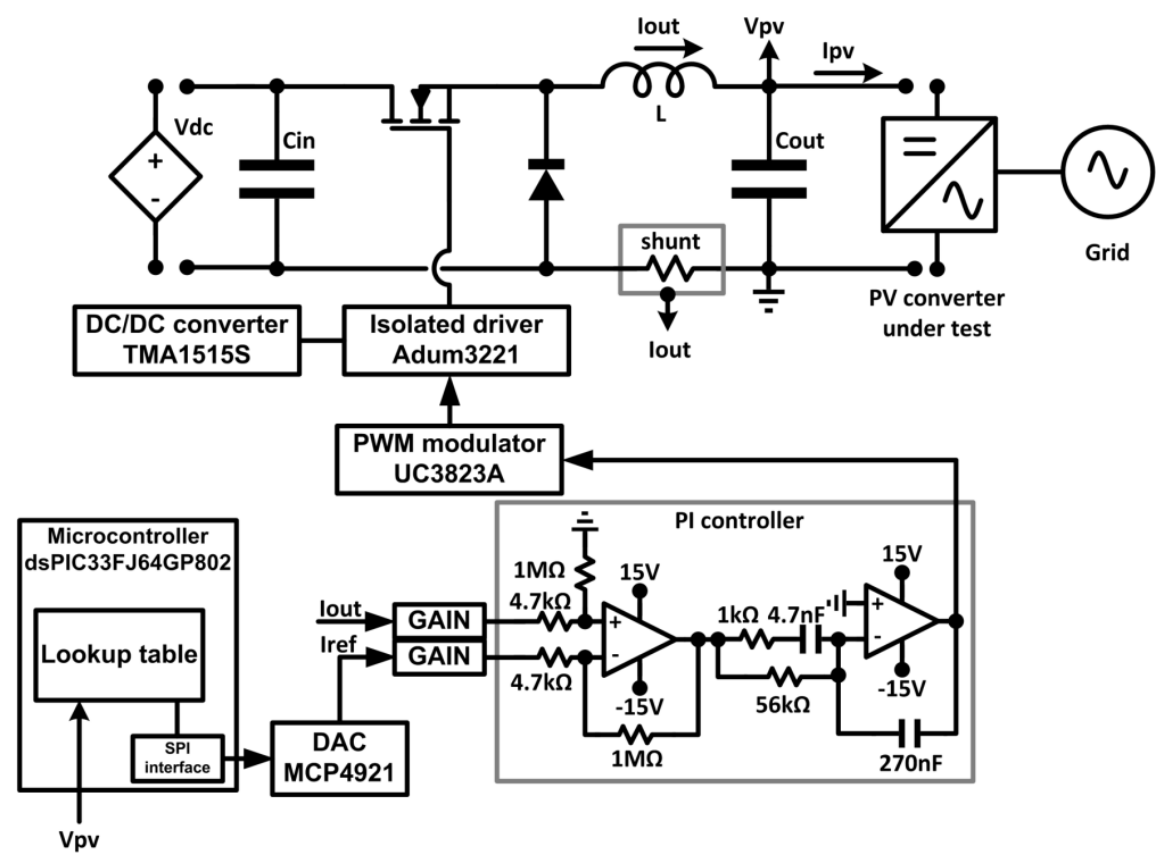

Figure 4: Simplified electronic scheme of the PV emulator based on a buck converter feeding a grid-connected microinverter.

The block diagram of the current control loop is shown in Figure 5, where Gi(s) is the transfer function of the current controller, Fm is the PWM modulator gain and $\mathrm{Ri}$ is the current sensing gain. The open loop gain of the current loop, Ti(s), is also shown in Figure 5. The dynamic model of the current loop is explained in reference [20]. 


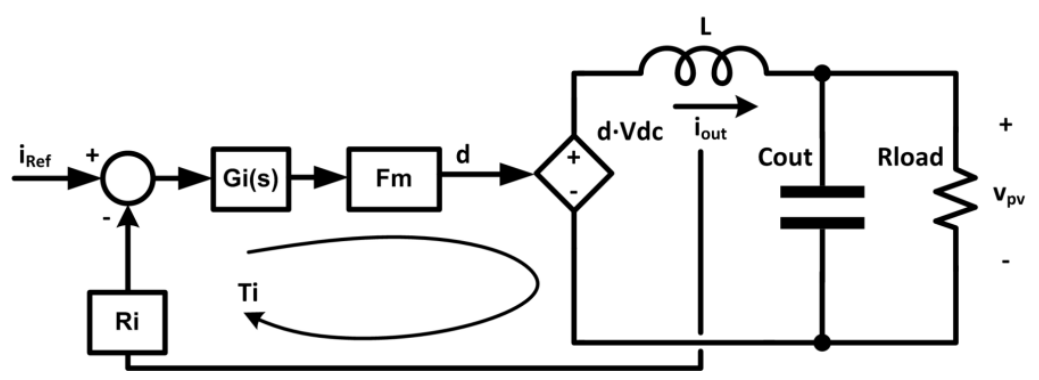

Figure 5: Average mode current control loop of the buck.

The mathematical model of the power stage of the buck converter and all the transfer functions used to adjust the control loop are summarized in Table 1, where Fm is the gain of the PWM modulator ( $\left.\mathrm{Fm}=0.56 \mathrm{~V}^{-1}\right)$, $\mathrm{Ri}$ is the current sensing gain $(\mathrm{Ri}=0.02 \Omega)$. RLOAD is calculated according to the voltage and power delivered to the PV converter under test: $\mathrm{RLOAD}=\mathrm{V}_{\mathrm{PV}}{ }^{2} / \mathrm{P}_{\mathrm{PV}}$. In the transfer function of the current controller, $\mathrm{Gi}(\mathrm{s})$, $\mathrm{w}_{\mathrm{i}}$ is the integrator gain, and $\mathrm{w}_{\mathrm{z}}$ and $\mathrm{w}_{\mathrm{p}}$ are the zero and pole (in rad/s), respectively.

It can be observed that the value of the dc-link capacitance (Cdc-link) of the converter connected to the emulator has taken into account in the duty cicle to inductor current response (Table 1$)$. However, the zero $1 /\left(\mathrm{R}_{\mathrm{LOAD}} \cdot\left(\mathrm{C}_{\text {out }}+\mathrm{C}_{\mathrm{dc}-\text {-link }}\right)\right)$ does not significantly affect this transfer function in the medium frequency range, near the crossover frequency. So, the stability is guaranteed over large variations of $\mathrm{C}_{\mathrm{dc}-\text { link }}$.

It is necessary to adjust the sensing gain (Ri) of the PV source emulator in order to adjust the $\mathrm{AD}$ converter to the output voltage range in order to obtain the maximum resolution. The adjustment of the sensing gain is done by means of a digital potentiometer.

The input voltage value (Vdc) can be adjusted to be compatible with different laboratory power supplies. Since the current-loop open loop gain, Ti(s), is strongly affected by the input voltage (Vdc), the parameter wi of the current regulator needs to be automatically adjusted (by means of the microncontroller) for each different configuration of the emulator. In the experimental results of this paper the emulator is configured as a single PV module (Vdc=60 V, Pmax=220 W). The current controller is adjusted to obtain a crossover frequency of the current-loop open loop gain, $T_{i}(s)$, around $10 \mathrm{kHz}$ for any value of Vdc, thus having a much higher bandwidth than the voltage loop of PV inverters (which is about 5-20 Hz). The high bandwidth of the PV emulator "seen" by the PV converter under test allows a reliable evaluation of the PV system under dynamic conditions. When the single PV module is being emulated with $\mathrm{Vdc}=60 \mathrm{~V}$ the adjustment values of the current regulator are: $\mathrm{wi}=13.2 \mathrm{rad} / \mathrm{s}, \mathrm{wz}=3.7$ $\mathrm{rad} / \mathrm{s}$, wp $=212.8 \mathrm{rad} / \mathrm{s}$. For other values of Vdc the value of wi varies in indirect proportion to Vdc, whereas the values of wz and wp are kept constant. The values of Vdc and wi programmed are shown in Table 2.

The Bode plot of the transfer function $\mathrm{T}_{\mathrm{i}}(\mathrm{s})$ is used to adjust the current controller. The stability of the system is guaranteed if the following criteria are achieved: the 
crossover frequency (gain=0 $\mathrm{dB}$ ) is below half the switching frequency, the phase margin (difference between -180deg and phase at the crossover frequency) is higher than $45 \mathrm{deg}$ and the gain margin $5 \mathrm{~dB}$ (the attenuation when the phase is $-180 \mathrm{deg}$ is $-5 \mathrm{~dB}$ ). The Bode plots of $T_{i}(s)$ for the whole output voltage range are depicted in Figure 6 . It is observed that the values of the crossover frequency $(10 \mathrm{kHz})$ and the stability margins (Phase Margin=70.5 deg, Gain Margin>20 dB) are kept in the whole range.
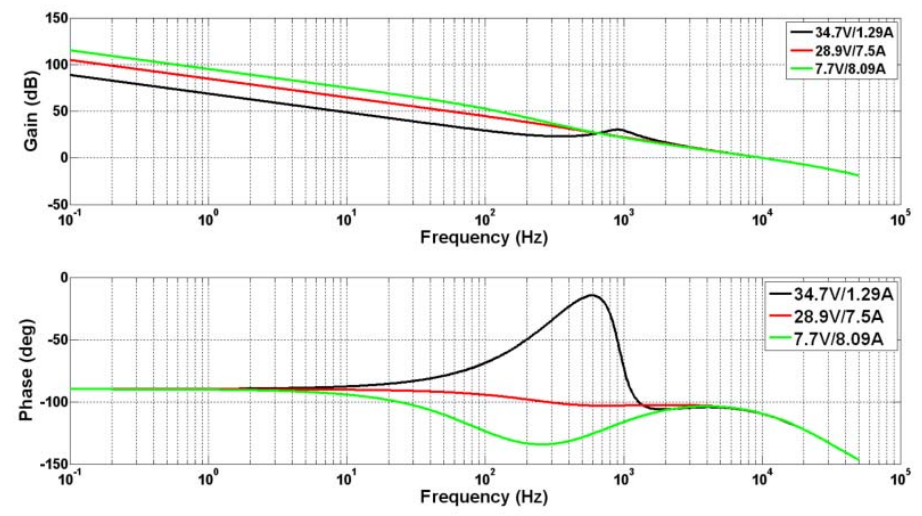

Figure 6: Bode plots of the current loop gain, $\mathrm{T}_{\mathrm{i}}(\mathrm{s})$, for different values of the output voltage Vpv. UP: gain, dB. LOW: phase, deg.

\section{Experimental results}

A prototype of the proposed PV emulator based on a buck converter has been designed and implemented for evaluating its performance. A photograph of the prototype is shown in Figure 7. The emulator can reproduce the behavior of a single photovoltaic source under different irradiance levels and temperatures, with a maximum output power of $3000 \mathrm{~W}$. In order to validate the emulator, the behavior a single photovoltaic module of $220 \mathrm{~W}$ under different irradiance levels and temperatures has been tested.

The I-V of the PV source curves has been stored in a lookup table inside the microcontroller. The ADC senses the output voltage and, taking into account the preprogrammed irradiance level and temperature, sets the current reference using the corresponding I-V lookup table. Steps in the reference current are avoided using linear interpolation between points of the lookup table. 


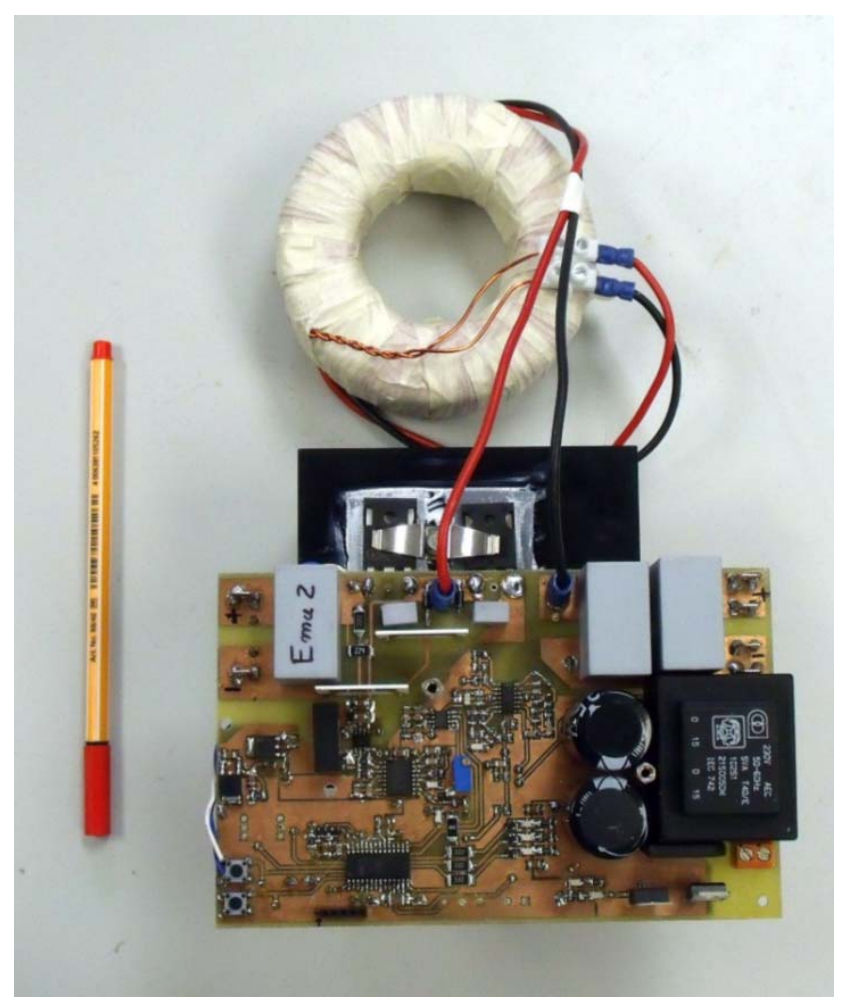

Figure 7: Photovoltaic source emulator

The experimental setup to test the static characteristics of the PV source emulator is depicted in Fig. 8. The prototype is connected to a programmable electronic load (CHROMA model 63803). The electronic load is configured in constant-voltage mode, emulating an inverter voltage control loop, which regulates the output voltage of the PV emulator. The emulator is powered from an external power source of $60 \mathrm{Vdc}$.

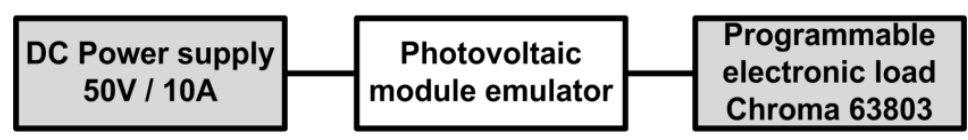

Figure 8: Experimental setup

The time domain step response of the buck converter is tested. Being the electronic load configured in constant voltage mode, the PV source emulator applies steps to the current reference. Experimental results are shown in Figure 9 for different operating areas: high current-low voltage, low current-high voltage and high current-high voltage. The figure shows how the inductor current (I $\mathrm{I}_{\text {OuT }}$, green trace) can be used to control the PV emulated current ( $I_{P V}$, pink trace) and justifies the use of an output dc-capacitor (that of the LC filter), as it absorbs the high-frequency current ripple produced by the switching converter. 

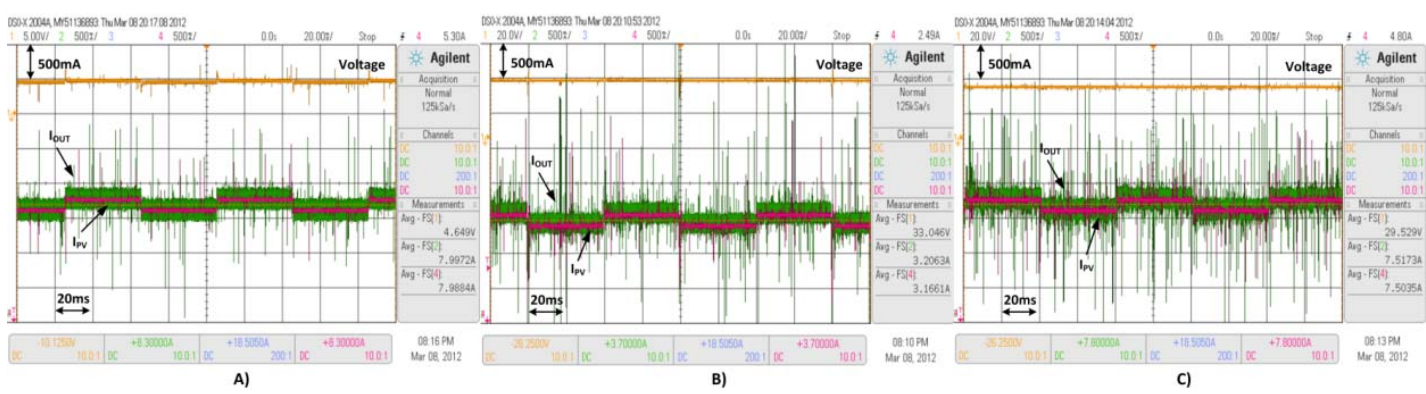

Figure 9: Time domain current and voltage waveforms of the buck converter. A) high current-low voltage, 8A/4.7V. B) low current-high voltage, 3.2A/33V. C) high currenthigh voltage, $7.5 \mathrm{~A} / 29.5 \mathrm{~V}$

If the reference voltage of the programmable electronic load, which agrees with the emulator output voltage, is varied along the whole output voltage range of the electronic load (minimum voltage: 7V) for different irradiance levels and for different temperatures, it can be observed that the output current fits the curves of the programmed photovoltaic source (Figures 10 and 11). The plotted curves in these figures is obtained from the voltage-current data provided by the datasheet of the PV module. Note that the lowest voltage of the experimental data is limited by the electronic load.
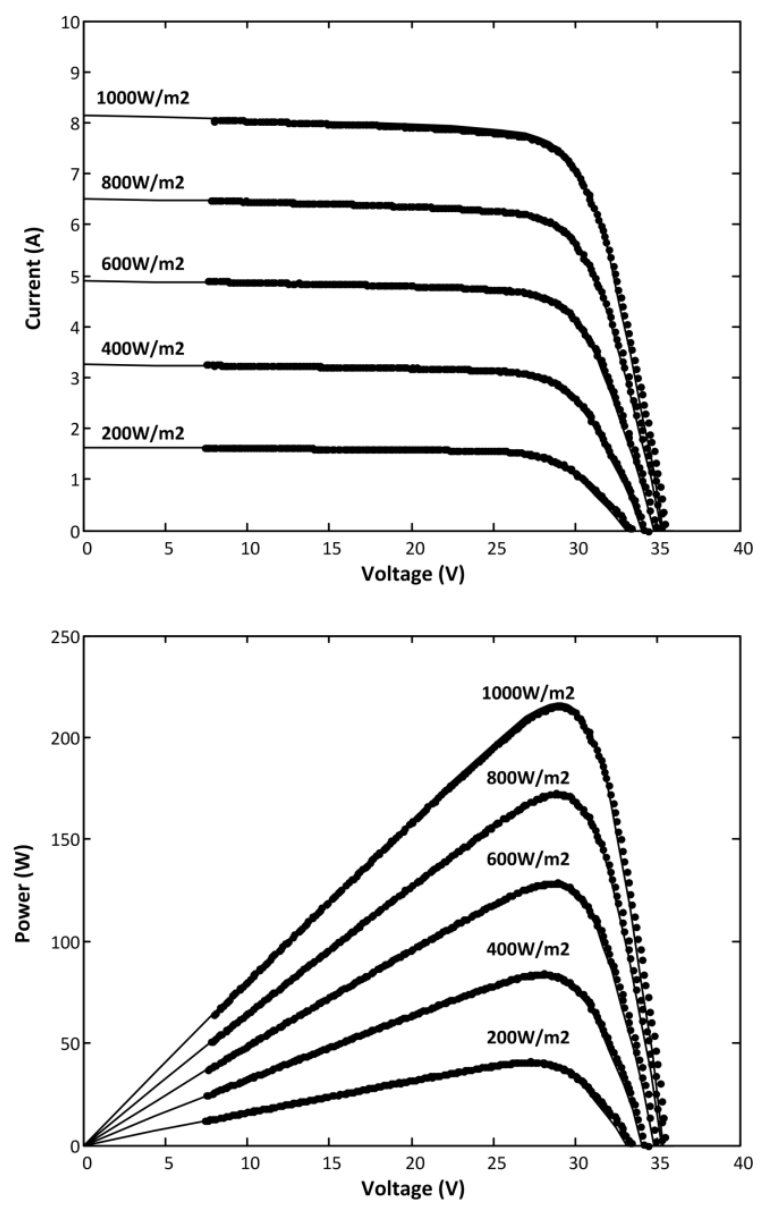

Figure 10: Model (lines) and experimental (dots) I-V and P-V curves of the emulator at different irradiance levels. The emulated ambient temperature is $25^{\circ} \mathrm{C}$. 

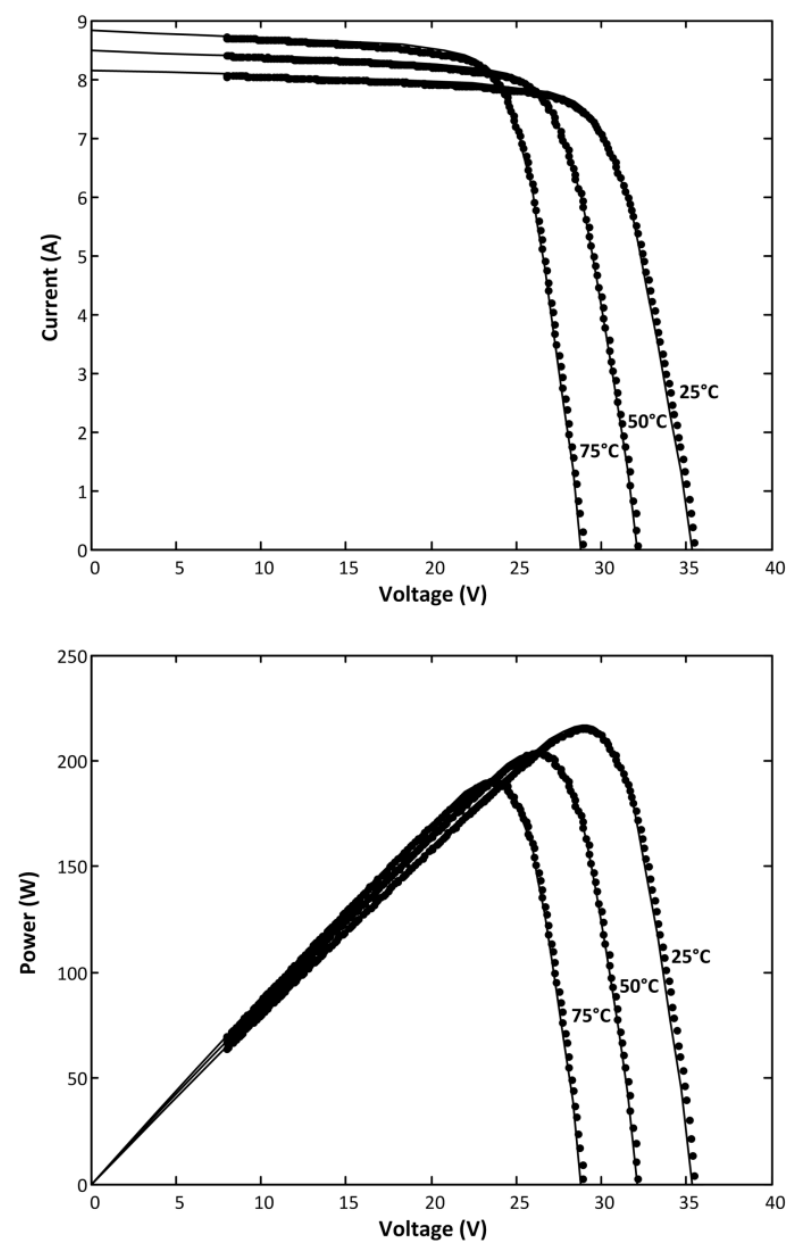

Figure 11: Model (lines) and experimental (dots) I-V and P-V curves of the emulator at different temperatures. The emulated irradiance is $1000 \mathrm{~W} / \mathrm{m}^{2}$.

To test the performance of the emulator under dynamic irradiance changes the programmable electronic load is configured in constant voltage mode. Then, an irradiance step is emulated. The irradiance steps applied are of $200 \mathrm{~W} / \mathrm{m}^{2}$ with a falling time of 4 seconds. This test is done at different voltages: constant current region (15V), near the maximum power point (28V) and constant voltage region (32V). Oscilloscope captures for these irradiance steps are shown in Figure 12, Figure 13 and Figure 14. In order to check if the captured output voltage and output current fits the curves of the emulated photovoltaic source, a 3-D plot with the I-V and P-V curves is shown in Figure 15. The plotted surface represents the data current-voltage-irradiance of the curves introduced in the microcontroller. The dots represent the data captured with the oscilloscope for $15 \mathrm{~V}, 28 \mathrm{~V}$ and $32 \mathrm{~V}$. 


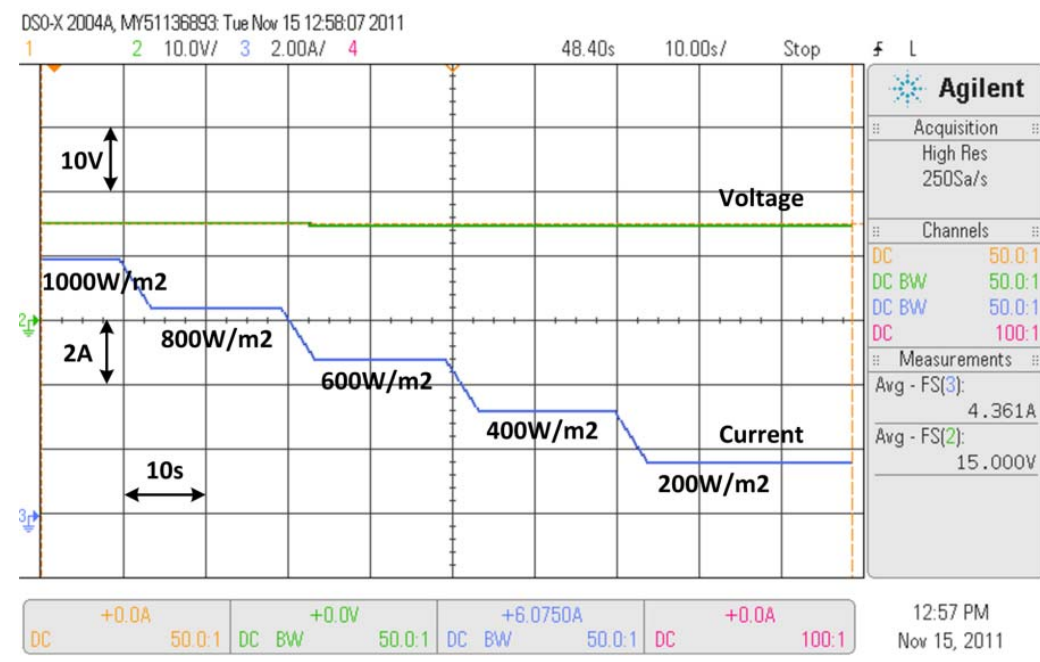

Figure 12: Irradiance steps at a constant voltage: constant current region (15V).

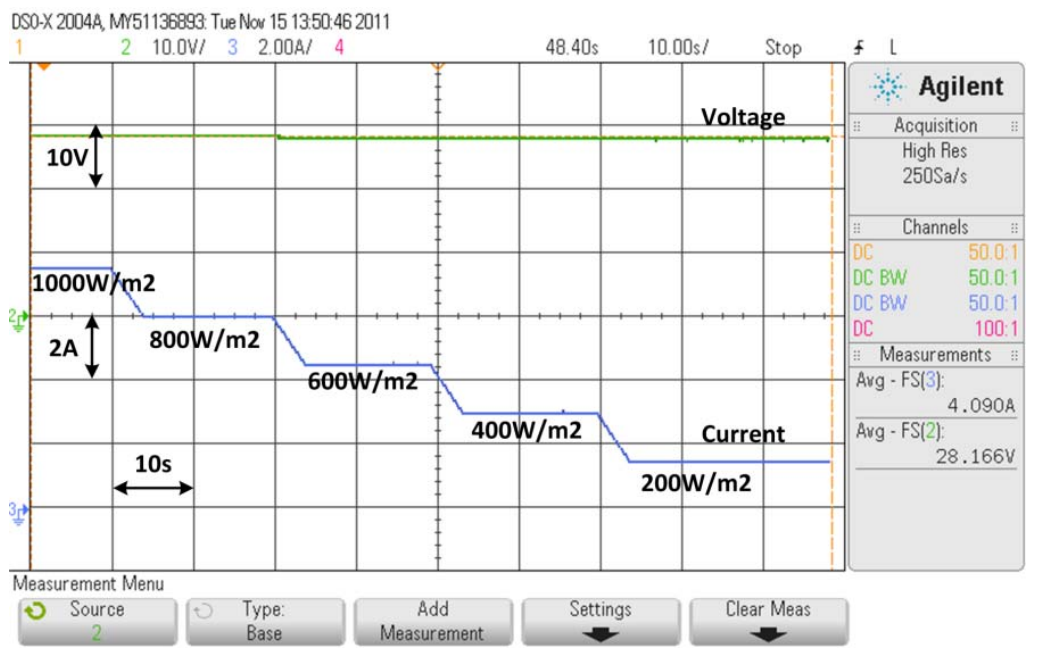

Figure 13: Irradiance steps at a constant voltage: near the MPP (28V).

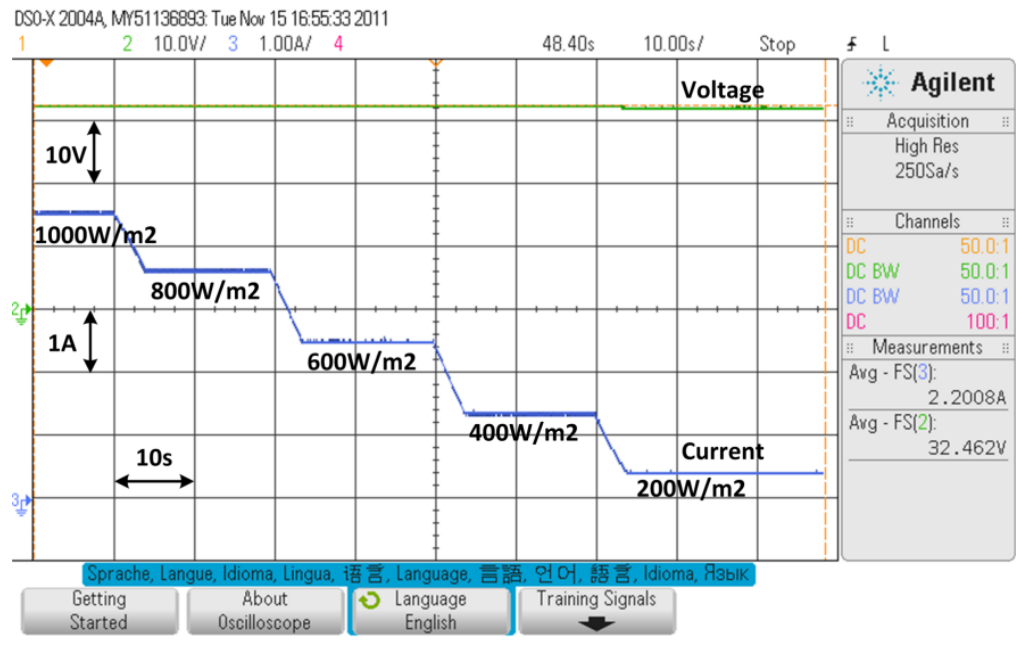

Figure 14: Irradiance steps at constant voltage: constant voltage region (32V). 

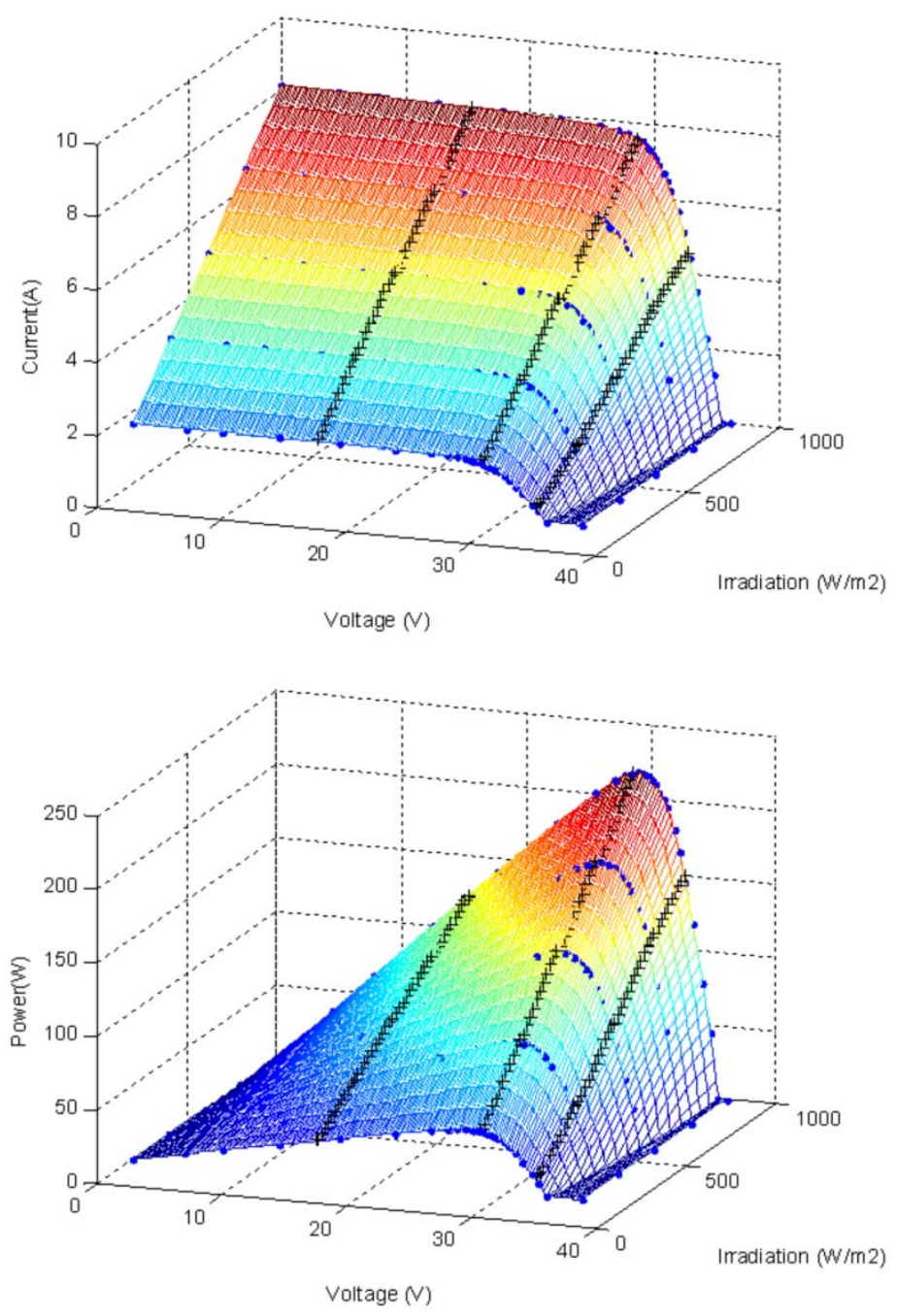

Figure 15: Curves of the emulated PV module (surface) and experimental data (dots) at irradiance steps.

In the next test of the PV emulator, the prototype is connected to a grid-connected single-phase microinverter of $230 \mathrm{~W}$ output power. The microinverter is a cascaded double stage topology (DC/DC followed by DC/AC converter), whose control loops are designed to regulate its input DC voltage and the grid injected current [3]. The microinverter MPPT algorithm varies the reference of its input voltage (i.e. the emulator output voltage) to track the MPP of the PV source, i.e. the PV emulator in this test. The algorithm used is the classical Perturb \& Observe (P\&O) [21], updated at $50 \mathrm{~Hz}$ with a voltage step of $1 \mathrm{~V}$. The energy obtained from the photovoltaic emulator is injected into the grid by means of the microinverter (Figure 16), whose characteristics are summarized in Table 3. 


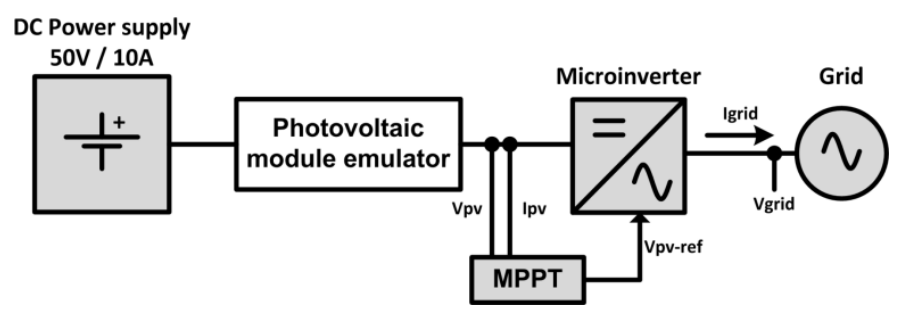

Figure 16: Experimental setup.

The PV emulator is used for the characterization of the MPPT performance of the microinverter at the following operating conditions of the emulated PV source: $1000 \mathrm{~W} / \mathrm{m}^{2}$ and $25^{\circ} \mathrm{C}$. Under these conditions the MPP is $\mathrm{V}_{\mathrm{PV} \_\mathrm{MPP}}=28.9 \mathrm{~V}$, IPV_MPP $=7.5 \mathrm{~A}$. The voltage and current provided by the emulator, $\mathrm{V}_{\mathrm{PV}}$ and $\mathrm{I}_{\mathrm{PV}}$, are shown in Figure 17. It can be observed that by the action of the MPPT algorithm the microinverter input voltage, $\mathrm{V}_{\mathrm{PV}}$, is varied to track the MPP of the emulated photovoltaic source.

In the I-V curve of any real PV source it holds that the absolute value of the negative slope is lower at the left side of the MPP than at the right side of the MPP. Therefore, when the MPPT algorithm produces negative voltage steps of $\mathrm{V}_{\mathrm{PV}}$ that push this voltage below $\mathrm{V}_{\mathrm{PV} \_\mathrm{MPP}}$, positive current steps of decreasing size are observed. This dynamic behavior is reproduced by the emulator when it feeds the microinverter, as it is shown in Figure 18.

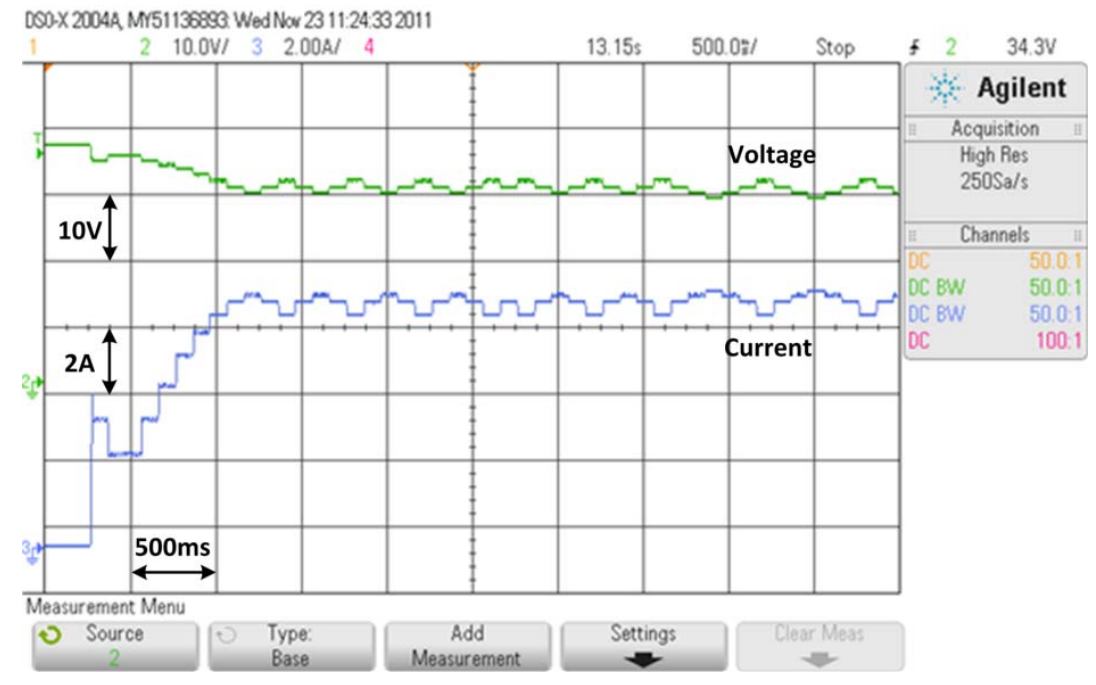

Figure 17: MPPT algorithm $\left(1000 \mathrm{~W} / \mathrm{m}^{2}, 25^{\circ} \mathrm{C}\right)$. 


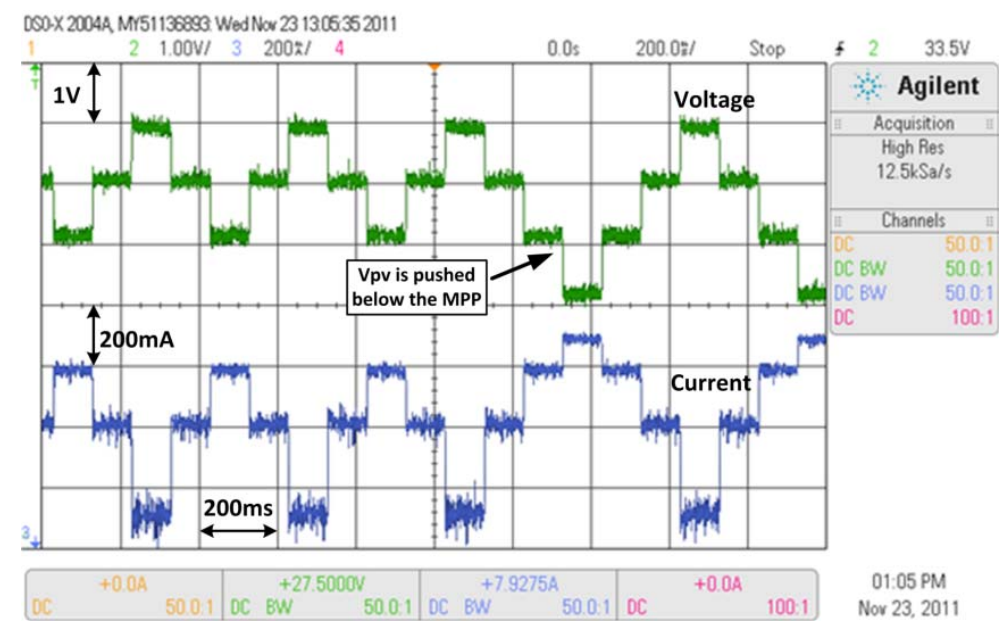

Figure 18: Detail of the voltage and current steps around the MPP produced by the microinverter MPPT algorithm. $\left(1000 \mathrm{~W} / \mathrm{m}^{2}, 25^{\circ} \mathrm{C}\right)$

The quality of the MPPT algorithm strongly depends on the minimum voltage step size of $\mathrm{V}_{\mathrm{PV}}$ that can be applied in each iteration [22]. The smaller this step size, the smaller are the dynamic deviations from the PV source MPP, which allows a better extraction of the available PV energy over the time. The emulator presented in this paper is able to respond to $100 \mathrm{mV}$ voltage steps, as it is shown in Figure 19. The emulator responds to steps lower than the $0.25 \%$ of its full scale.

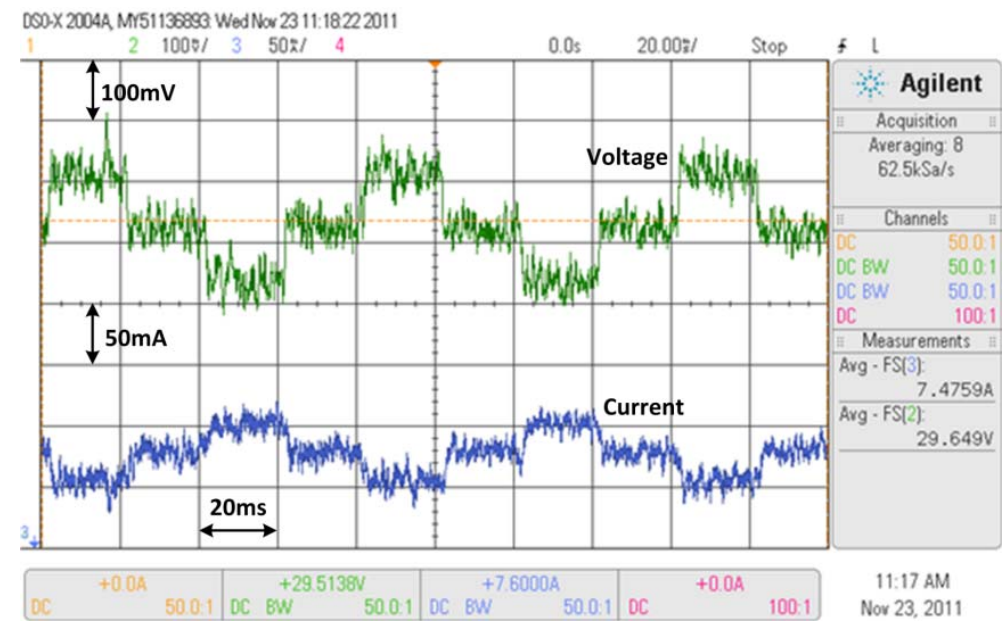

Figure 19: Detail of the voltage and current steps around the MPP produced by the microinverter MPPT algorithm working with $100 \mathrm{mV}$ voltage steps $\left(1000 \mathrm{~W} / \mathrm{m}^{2}, 25^{\circ} \mathrm{C}\right)$.

Another parameter to characterize the quality of the MPPT algorithm is the response to transients of the PV source irradiance or temperature. Three different transient responses have been tested with the emulator feeding the microinverter, which is running the MPPT algorithm: a slow, 10 seconds, transient of the irradiance (Figure 20 and Figure 21), a fast, 1 second, transient of the irradiance (Figure 22 and Figure 23), and a temperature transient (Figure 24 and Figure 25). Note that $\mathrm{V}_{\mathrm{PV} \_\mathrm{MPP}}$ varies very slightly (from $28.9 \mathrm{~V}$ to $28.4 \mathrm{~V}$ ) to the irradiance steps shown in Figure 20, so that its variation is almost imperceptible at the vertical scale of the oscilloscope. These figures 
show that the emulator can be used to evaluate the performance of the MPPT algorithm of a microinverter under these transient conditions.

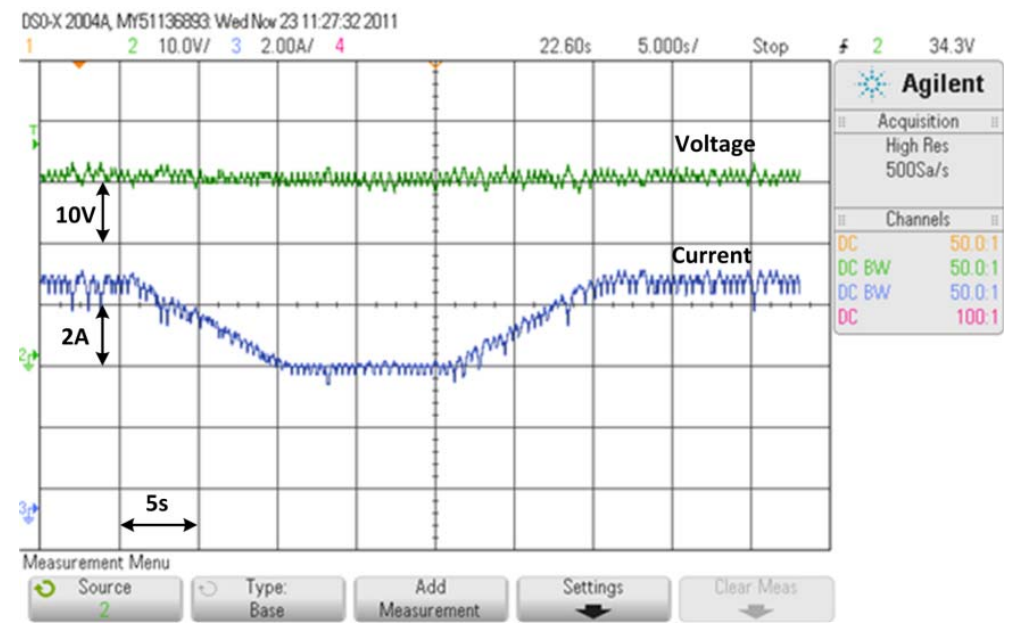

Figure 20: MPPT evolution under irradiance steps from $1000 \mathrm{~W} / \mathrm{m}^{2}$ to $600 \mathrm{~W} / \mathrm{m}^{2}$ and back to $1000 \mathrm{~W} / \mathrm{m}^{2}$. Transition time: 10 seconds. The ambient temperature is $25^{\circ} \mathrm{C}$.

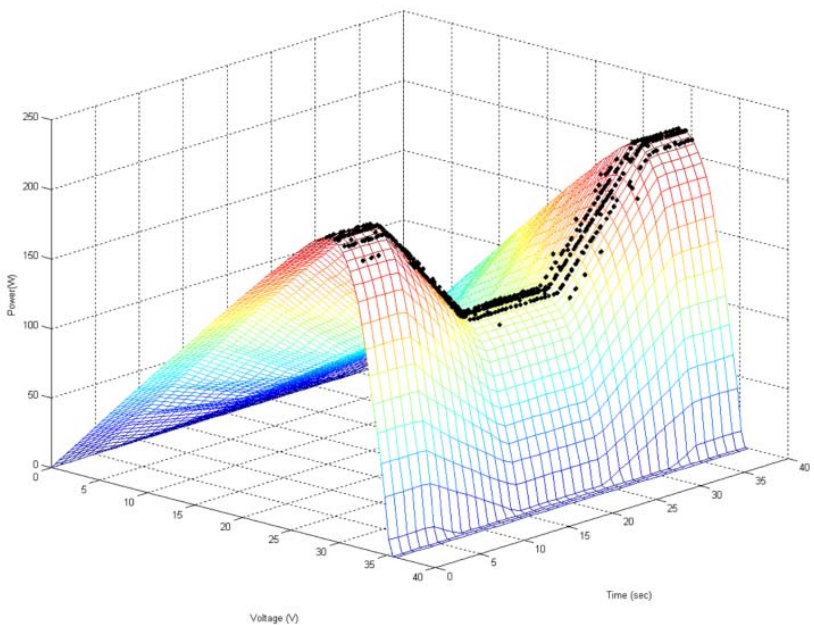

Figure 21: Irradiance steps from $1000 \mathrm{~W} / \mathrm{m}^{2}$ to $600 \mathrm{~W} / \mathrm{m}^{2}$ and back to $1000 \mathrm{~W} / \mathrm{m}^{2}$ plotted over the power-voltage surface. Transition time: 10 seconds. The ambient temperature is $25^{\circ} \mathrm{C}$. Dots represent the MPPT evolution. 


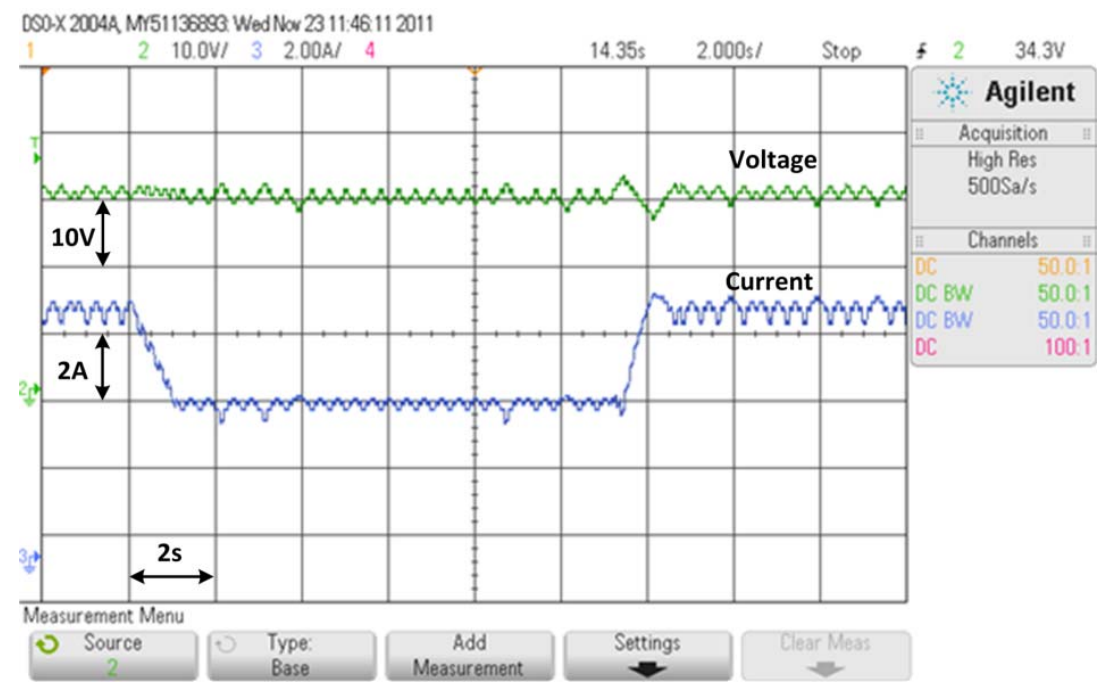

Figure 22: MPPT evolution under irradiance steps from $1000 \mathrm{~W} / \mathrm{m}^{2}$ to $600 \mathrm{~W} / \mathrm{m}^{2}$ and back to $1000 \mathrm{~W} / \mathrm{m}^{2}$. Transition time: 1 second. The ambient temperature is $25^{\circ} \mathrm{C}$.

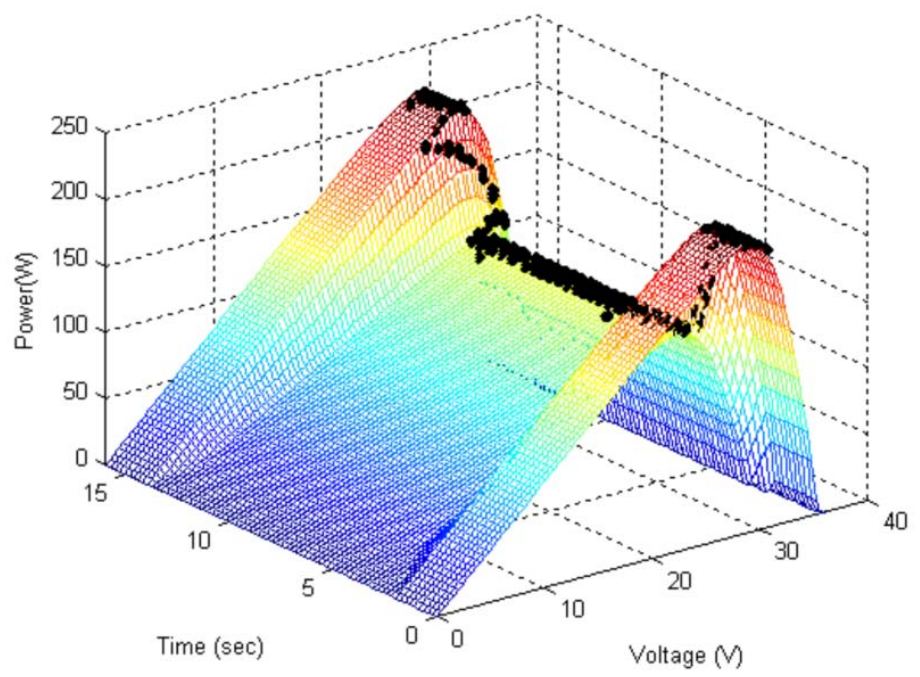

Figure 23: Irradiance steps from $1000 \mathrm{~W} / \mathrm{m}^{2}$ to $600 \mathrm{~W} / \mathrm{m}^{2}$ plotted over the power-voltage surface. Transition time: 1 second. The ambient temperature is $25^{\circ} \mathrm{C}$. Dots represent the MPPT evolution. 


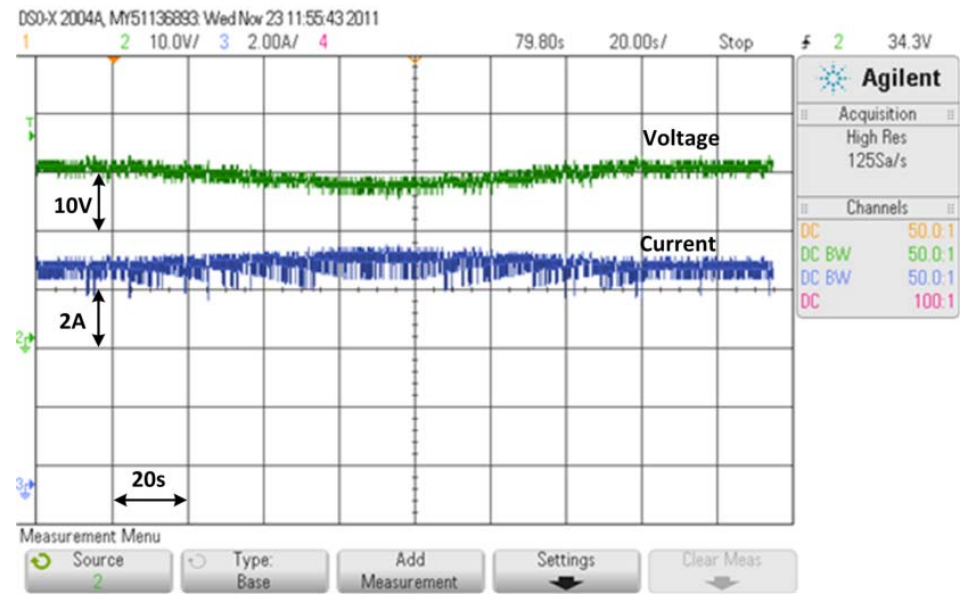

Figure 24: MPPT evolution under temperature change from $25^{\circ} \mathrm{C}$ to $55^{\circ} \mathrm{C}$ and back to $25^{\circ} \mathrm{C}$ in 60 seconds. The emulated irradiance is $1000 \mathrm{~W} / \mathrm{m}^{2}$.

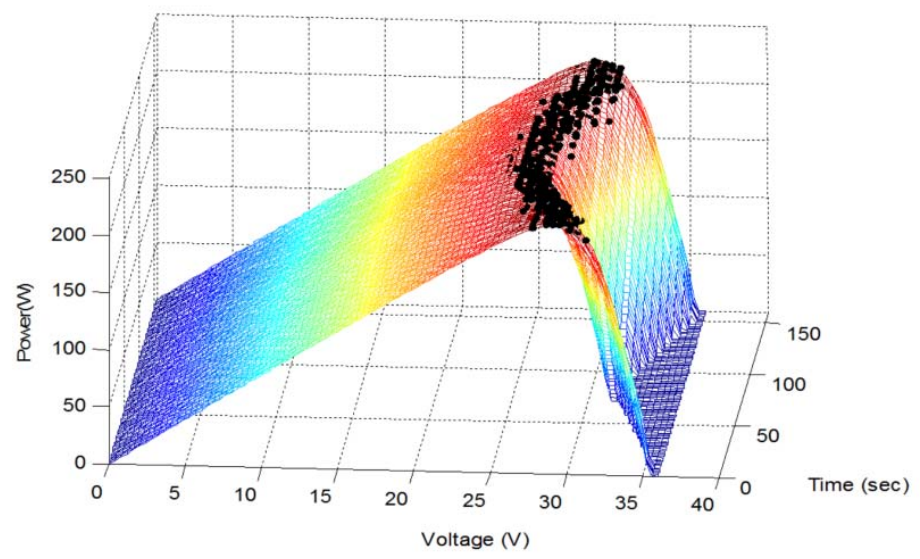

Figure 25: Temperature change from $25^{\circ} \mathrm{C}$ to $55^{\circ} \mathrm{C}$ and back to $25^{\circ} \mathrm{C}$ in 60 seconds plotted over the power-voltage curve. Dots represent the MPPT evolution.

When testing the performance of MPPT algorithms it is a usual practice to test the power converter for a long period of time, emulating irradiance variations during one day. It is possible to program inside the microcontroller a curve like that shown in Figure 26, which represents the irradiance level during one sunny day of winter [6]. 


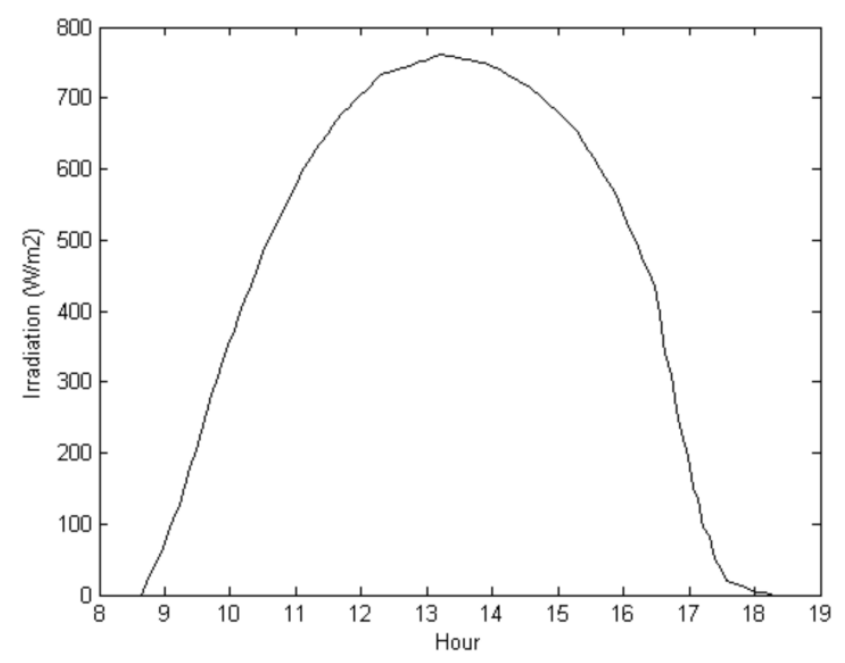

Figure 26: Evolution of the irradiance level during one day (January)

The MPPT algorithm of the microinverter is tested with the photovoltaic emulator connected at its input. The power and energy obtained from the emulator are shown in Figure 27. The output power plotted over the power-voltage curve is shown in Figure 28.
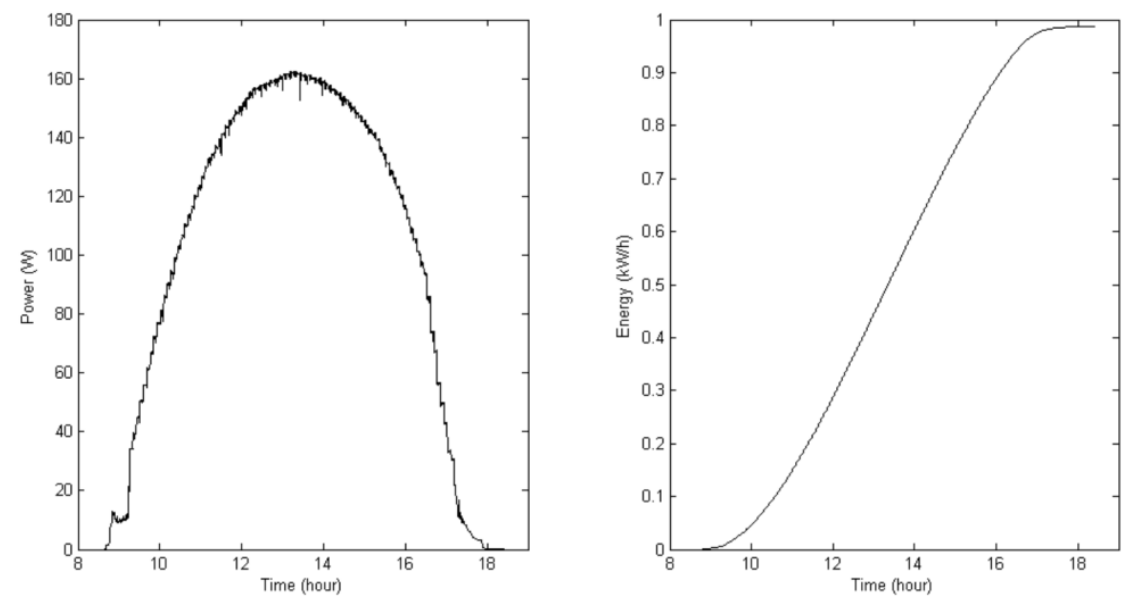

Figure 27: Power and energy during one day obtained from the PV emulator feeding the microinverter. 


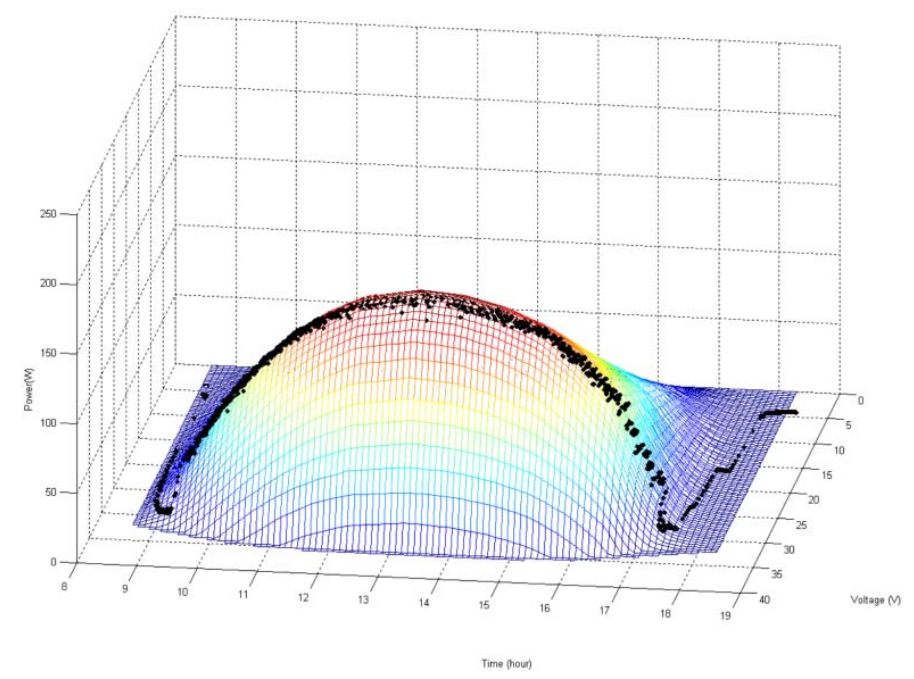

Figure 28: Power over one day plotted over the power-voltage surface

\section{Conclusions}

In order to characterize and evaluate photovoltaic electronic power converters and facilities, it is necessary to provide a power source that emulates the current-voltage characteristics of a photovoltaic source. An emulator can simulate every weather or temperature condition and PV modules of different manufacturers. The tests can be repeated in the same conditions easily.

Commercial PV emulators present several drawbacks, as a high cost and the impossibility of emulating rapidly changing atmospheric conditions. In this paper a buck DC-DC converter topology is selected as PV emulator, since it is efficient and inexpensive. The $3 \mathrm{~kW}$ photovoltaic emulator presented has been designed to have a current loop bandwidth of $10 \mathrm{kHz}$, much higher than the iteration speed of the usual MPPT algorithms of any PV converter under test. The control architecture is based on an analog average current loop and a voltage-to-current lookup table. The volume of the emulator is $1.7 \mathrm{dm}^{3}$ and its weight around $3 \mathrm{~kg}$. The production cost of this emulator could be lower than $\$ 210$.

An emulator prototype has been validated by means of simulation and experimental results. It has been demonstrated that the output current-voltage and voltage-power characteristics match the preprogrammed curves of the PV source. The prototype can emulate changes of irradiance and temperature with different dynamics. Finally, a gridconnected microinverter has been tested, showing how this inexpensive emulator can help to evaluate the performance of MPPT algorithms, both in fast transient conditions and in the long term. 
Summing up, the emulator proposed in this paper presents a low cost alternative to emulate the operation of PV sources and power converters in a laboratory under different operating conditions.

\section{Acknowledgement}

This work is supported by the Spanish Ministry of Science and Innovation under grant ENE2009-13998-C02-02.

\section{References:}

[1] C. Prapanavarat, M. Barnes, and N. Jenkins, Investigation of the performance of a photovoltaic AC module. IEEE Proceedings - Generation, Transmission and Distribution, July2002, 149,(4): pp. 472-478. DOI: 10.1049/ip-gtd:20020141.

[2] E. Durán, J. M. Andújar, J. Galán, and M. Sidrach-de-Cardona, Methodology and experimental system for measuring and displaying I-V characteristic curves of PV facilities. Progress in Photovoltaics: Research and Applications, 2009, 17,(8): pp. 574-586. DOI: 10.1002/pip.909.

[3] G. Garcerá, R. González-Medina, E. Figueres, and J. Sandia, Dynamic modeling of DC-DC converters with peak current control in double-stage photovoltaic grid-connected inverters. International Journal of Circuit Theory and Applications. Available on-line, january 2011. DOI: 10.1002/cta.756.

[4] M. Piliougine, J. Carretero, L. Mora-López, and M. Sidrach-de-Cardona, Experimental system for current-voltage curve measurement of photovoltaic modules under outdoor conditions. Progress in Photovoltaics: Research and Applications, 2011, 19,(5): pp. 591-602. DOI: 10.1002/pip.1073.

[5] M. Camino-Villacorta, M. A. Egido-Aguilera, and P. Díaz, Test procedures for maximum power point tracking charge controllers characterization. Progress in Photovoltaics: Research and Applications, 2011. DOI: 10.1002/pip.1139.

[6] P. Sanchis, J. López, A. Ursúa, E. Gubía, and L. Marroyo, On the testing, characterization, and evaluation of PV inverters and dynamic MPPT performance under real varying operating conditions. Progress in Photovoltaics: Research and Applications, 2007, 15,(6): pp. 541-556. DOI: 10.1002/pip.763.

[7] D. Dolan, J. Durago, J. Crowfoot, and Taufik, Simulation of a photovoltaic emulator, North American Power Symposium (NAPS), 2010, pp. 1-7. DOI: 10.1109/NAPS.2010.5618941.

[8] S. B. Kjaer, J. K. Pedersen, and F. Blaabjerg, A review of single-phase gridconnected inverters for photovoltaic modules. IEEE Transactions on Industry Applications, Sept.2005, 41,(5): pp. 1292-1306. DOI: 10.1109/TIA.2005.853371. 
[9] D. Meneses, O. Garcia, P. Alou, J. A. Oliver, R. Prieto, and J. A. Cobos, Singlestage grid-connected forward microinverter with boundary mode control, Energy Conversion Congress and Exposition (ECCE) 2011, pp. 2475-2480. DOI: 10.1109/ECCE.2011.6064097.

[10] N. Kondrath and M. K. Kazimierczuk, Comparison of Wide- and HighFrequency Duty-Ratio-to-Inductor-Current Transfer Functions of DC-DC PWM Buck Converter in CCM. IEEE Transactions on Industrial Electronics, Jan.2012, 59,(1): pp. 641-643. DOI: 10.1109/TIE.2011.2134053.

[11] T. T. Yun, D. S. Kirschen, and N. Jenkins, A model of PV generation suitable for stability analysis. IEEE Transactions on Energy Conversion, Dec.2004, 19,(4): pp. 748-755. DOI: 10.1109/TEC.2004.827707.

[12] A. Mäki, S. Valkealahti, and J. Leppäaho, Operation of series-connected siliconbased photovoltaic modules under partial shading conditions. Progress in Photovoltaics: Research and Applications, 2011. DOI: 10.1002/pip.1138.

[13] M. G. Villalva, J. R. Gazoli, and E. R. Filho, Comprehensive Approach to Modeling and Simulation of Photovoltaic Arrays. IEEE Transactions on Power Electronics, May2009, 24,(5): pp. 1198-1208. DOI: 10.1109/TPEL.2009.2013862.

[14] L. Shengyi and R. A. Dougal, Dynamic multiphysics model for solar array. IEEE Transactions on Energy Conversion, June2002, 17,(2): pp. 285-294. DOI: 10.1109/TEC.2002.1009482.

[15] A. Koran, K. Sano, K. Rae-Young, and L. Jih-Sheng, Design of a photovoltaic simulator with a novel reference signal generator and two-stage LC output filter, Energy Conversion Congress and Exposition, 2009. ECCE 2009. IEEE 2009, pp. 319-326. DOI: 10.1109/ECCE.2009.5316190.

[16] R. Orduz, J. Solórzano, M. Á. Egido, and E. Román, Analytical study and evaluation results of power optimizers for distributed power conditioning in photovoltaic arrays. Progress in Photovoltaics: Research and Applications, 2011, p. n/a. DOI: 10.1002/pip.1188.

[17] H. Mekki, A. Mellit, S. A. Kalogirou, A. Messai, and G. Furlan, FPGA-based implementation of a real time photovoltaic module simulator. Progress in Photovoltaics: Research and Applications, 2010, 18,(2): pp. 115-127. DOI: 10.1002/pip.950.

[18] N. Mohan, T. Undeland, and W. Robbins, Power Electronics: Converters, Applications and Design (3rd edn). 2003.

[19] G. Garcera, E. Figueres, M. Pascual, and J. M. Benavent, Robust model following control of parallel buck converters. IEEE Transactions on Aerospace and Electronic Systems, July2004, 40,(3): pp. 983-997. DOI: 10.1109/TAES.2004.1337469.

[20] V. Vorperian, Simplified analysis of PWM converters using model of PWM switch. Continuous conduction mode. IEEE Transactions on Aerospace and Electronic Systems, May1990, 26,(3): pp. 490-496. DOI: 10.1109/7.106126. 
[21] P. Packiam, N. K. Jain, and I. P. Singh, Microcontroller-based simple maximum power point tracking controller for single-stage solar stand-alone water pumping system. Progress in Photovoltaics: Research and Applications, 2011. DOI: 10.1002/pip.1207.

[22] F. Chuanzong and S. Shiping, Simulation studying of MPPT control by a new method for photovoltaic power system, Electrical and Control Engineering (ICECE), 2011 International Conference on 2011, pp. 1274-1278. DOI: 10.1109/ICECENG.2011.6057918. 


\begin{tabular}{|l|c|}
\hline PWM Modulator Gain & $F_{m}=\frac{1}{V p p}$ \\
\hline $\begin{array}{l}\text { Duty cycle to inductor } \\
\text { current response }\end{array}$ & $\frac{i_{\text {out }}}{d}(s)=\frac{V_{d c} \cdot\left(R_{L O A D} \cdot\left(C_{\text {out }}+C_{d c-l i n k}\right) \cdot s+1\right)}{R_{L O A D} \cdot\left(L \cdot\left(C_{\text {out }}+C_{d c-l i n k}\right) \cdot s^{2}+1\right)+L \cdot s}$ \\
\hline Current loop regulator & $G_{i}(s)=\frac{w_{i}}{s} \cdot \frac{1+\frac{s}{w_{z}}}{1+\frac{s}{w_{p}}}$ \\
\hline Current loop gain & $T_{i}(s)=\frac{i_{\text {out }}}{d}(s) \cdot F_{m} \cdot R_{i} \cdot G_{i}(s)$ \\
\hline
\end{tabular}

Table 1: Summary of transfer functions of CCM buck dc-dc converter with ACC 


\begin{tabular}{|c|c|c|}
\hline $\begin{array}{c}\text { Number of PV modules } \\
\text { being emulated }\end{array}$ & $\begin{array}{c}\text { Vdc } \\
\text { (volts) }\end{array}$ & wi \\
\hline 1 & 60 & 13.2 \\
\hline 2 & 120 & 6.6 \\
\hline$<=4$ & 240 & 3.3 \\
\hline$<=8$ & 400 & 1.98 \\
\hline$<=14$ & 540 & 1.47 \\
\hline
\end{tabular}

Table 2: Value of wi for different input voltage values. 


\begin{tabular}{|l|l|}
\hline MPP input voltage range ( $\left.\mathrm{V}_{\mathrm{PV}} \mathrm{MPP}\right)$ & $24-35 \mathrm{Vdc}$ \\
\hline Input current (I $\left.\mathrm{I}_{\mathrm{PV}} \mathrm{MPP}\right)$ & $8 \mathrm{~A}(\max )$ \\
\hline Output power & $230 \mathrm{~W}(\max )$ \\
\hline Switching frequency (dc/dc) & $24 \mathrm{kHz}$ \\
\hline Switching frequency (dc/ac) & $10 \mathrm{kHz}$ \\
\hline Nominal grid & $230 \mathrm{~V} / 50 \mathrm{~Hz}$ \\
\hline
\end{tabular}

Table 3: Double stage (dc-dc + dc-ac) microinverter characteristics 